\title{
Vuonna 2013 julkaistua kirjallisuudentutkimusta
}

\section{Väitöskirjat:}

Ahola, Suvi. Lukupiirien Suomi. Yhteisöllistä lukemista 149 suomalaisessa lukupiirissä 2009. Helsinki: Helsingin yliopisto. http://urn.fi/ URN:ISBN:978-952-10-8591-8.

Ameel, Lieven. Moved by the City. Experiences of Helsinki in Finnish Prose Fiction 1889-1941. Helsinki: University of Helsinki. http://urn.fi/ URN:ISBN:978-952-10-8862-9.

Degerman, Peter. "Litteraturen, det är vad man undervisar om". Det svenska litteraturdidaktiska fältet i förvandling. Åbo: Åbo Akademis förlag. http://urn.fi/ URN:ISBN:978-951-765-671-9.

Eskelinen, Helena. L'ekphrasis nei Romanzi della Rosa di Gabriele D’Annunzio. Helsinki: Università di Helsinki. http://urn.fi/URN:ISBN:978-952-10-8717-2.

Johansson, Carl-Eric. Brutal social demaskering. Om Kurt Salomonson, bilden av folkhemmet och offentligheterna. Tammerfors: Tampere University Press. http://urn.fi/ URN:ISBN:978-951-44-9170-2.

Järvelä, Juha. Kaksi maailmaa? Sukupuoli Mika Waltarin kirjailijakuvassa, teksteissä ja niiden vastaanotossa 1925-1939. Jyväskylä: Jyväskylän yliopisto. http://urn.fi/ URN:ISBN:978-951-39-5220-4.

Kaakinen Kaisa. Minding the Gap. Reading History with Joseph Conrad, Peter Weiss, and W. G. Sebald. Ithaca: Cornell University.

Kakko, Tommi. Failures by Design. The Transparent Author in English Satire from Marprelate to Pope. Tampere: Tampere University Press. http://urn.fi/ URN:ISBN:978-951-44-9101-6.

Kallionsivu, Mikko. Saiturin kuolema. Kuoleman kulttuuripoetiikkaa angloamerikkalaisessa fiktiossa myöhäiskeskiajalta nykypäivään. Tampere: Tampere University Press. http://urn.fi/URN:ISBN:978-951-44-9265-5.

Kurikka, Kaisa. Algot Untola ja kirjoittava kone. Turku: Eetos.

Lahtinen, Toni. Maan höyryävässä sylissä. Luonto, ihminen ja yhteiskunta Timo K. Mukan tuotannossa. Helsinki: WSOY.

Martikainen, Elina. Kirjoitettu sota. Sotadiskursseja suomalaisessa kaunokirjallisuudessa (1917-1995). Tampere: Tampere University Press. http://urn.fi/ URN:ISBN:978-951-44-9283-9.

Pehkoranta, Anne. Rewriting Loss: Melancholia, Ethics, and Aesthetics in Selected Works by Chuang Hua, Maxine Hong Kingston, and Fae Myenne Ng. Jyväskylä: Jyväskylän yliopisto. 
Riippa, Anne. Réécritures bibliques chez Paul Claudel, André Gide et Albert Camus. Une étude intertextuelle sur dix oeuvres littéraires. Helsinki: l'Université de Helsinki. http://urn.fi/URN:ISBN:978-952-10-8908-4.

Saarti, Jarmo. Kiinalaisen kaunokirjallisuuden suomennokset 1900-luvulla. Kääntämisen ja vastaanoton kulttuurinen konteksti. Jyväskylä: Jyväskylän yliopisto.

Tuori, Riikka. Karaite zèmīrōt in Poland-Lithuania. A Study of Paraliturgical Karaite Hebrew Poems from the Seventeenth and Eighteenth Centuries. Helsinki: University of Helsinki.

Welander, Martin. Grå verklighet, gyllne fantasi. Skapandets problematik i R.R. Eklunds aforistiska författarskap. Helsingfors: Helsingfors universitet. http://urn.fi/ URN:ISBN:978-952-10-8697-7.

Westerlund, Jasmine. Murtumia lasikellossa. Naisten kirjoittamat taiteilijaromaanit Suomessa 1900-luvun alkupuolella. Turku: Turun yliopisto. http://urn.fi/ URN:ISBN:978-951-29-5474-2.

\section{Monografiat:}

Ahvenjärvi, Kaisa \& Leena Kirstinä. Kirjallisuuden opetuksen käsikirja. Tietolipas 239. Helsinki: SKS.

Eväsoja, Minna. Teetaide ja runous. Wabi ja sabi japanilaisessa estetiikassa. Suomalaisen Kirjallisuuden Seuran toimituksia 1394. Helsinki: SKS.

Hökkä, Tuula. Tuoksuville vuorille. Naisrunoilijoiden poetiikkaa, modernismeja. Suomalaisen Kirjallisuuden Seuran toimituksia 1341. Helsinki: SKS.

Järvelä, Juha. Waltari ja sukupuolten maailmat. Helsinki: Avain.

Kukkonen, Karin. Contemporary Comics Storytelling. Frontiers of Narrative. Lincoln: University of Nebraska Press.

Kukkonen, Karin. Studying Comics and Graphic Novels. Oxford: Wiley-Blackwell.

Lyytikäinen, Pirjo. Leena Krohn ja allegorian kaupungit. Suomalaisen Kirjallisuuden Seuran toimituksia 1392. Helsinki: SKS.

Mikkonen, Jukka. The Cognitive Value of Philosophical Fiction. Bloomsbury Studies in Philosophy. London \& New York: Bloomsbury.

Oikkonen, Venla. Gender, Sexuality and Reproduction in Evolutionary Narratives. London: Routledge.

Riikonen, H. K. Im Dienste von Sprache und Literatur. Mémoires de la Société Néophilologique 88. Helsinki: La Société Néophilologique.

Seppälä, Mikko-Olavi \& Riitta Seppälä. Aale Tynni. Hymyily, kyynel, laulu. Helsinki: WSOY.

Sklar, Howard. The Art of Sympathy in Fiction. Forms of Ethical and Emotional Persuasion. Linguistic Approaches to Literature 15. Amsterdam: John Benjamins. 
Steinby, Liisa. Kundera and Modernity. Layfayette: Purdue University Press.

Tiittula, Liisa \& Pirkko Nuolijärvi. Puheen illuusio suomenkielisessä kaunokirjallisuudessa. Suomalaisen Kirjallisuuden Seuran toimituksia 1401. Helsinki: SKS.

Toikkanen, Jarkko. The Intermedial Experience of Horror. Suspended Failures. Basingstoke: Palgrave Macmillan.

\section{Artikkelikokoelmat ja toimitetut teokset:}

Haapala, Vesa \& Juhani Sipilä (toim.). Kiviaholinna. Suomalainen romaani. Helsinki: Avain.

Hallila, Mika, Yrjö Hosiaisluoma, Sanna Karkulehto, Leena Kirstinä \& Jussi Ojajärvi (toim.). Suomen nykykirjallisuus 1-2. Suomalaisen Kirjallisuuden Seuran toimituksia 1390. Helsinki: SKS.

Hyvärinen, Matti, Mari Hatavara \& Lars-Christer Hydén (toim.). The Travelling Concepts of Narrative. Studies in Narrative 18. Amsterdam: John Benjamins.

Isomaa, Saija, Pirjo Lyytikäinen, Kirsi Saarikangas \& Renja Suominen-Kokkonen (eds). Imagining Spaces and Places. Newcastle upon Tyne: Cambridge Scholars Publishing.

Kivistö, Sari \& H. K. Riikonen (toim.). Mitä jokaisen tulee tietää antiikista. Kreikka \& Rooma. Helsinki: Avain.

Koivisto, Aino \& Elise Nykänen (toim.). Dialogi kaunokirjallisuudessa. Tietolipas 242. Helsinki: SKS.

Kuismin, Anna \& M. J. Driscoll (eds). White Field, Black Seeds. Nordic Literacy Practices in the Long Nineteenth Century. Studia Fennica Litteraria 7. Helsinki: SKS.

Laitinen, Lea \& Kati Mikkola (toim.). Kynällä kyntäjät. Kansan kirjallistuminen 1800-luvun Suomessa. Suomalaisen Kirjallisuuden Seuran toimituksia 1370. Helsinki: SKS.

Mehtonen, P. M. \& Matti Savolainen (eds). Gothic Topographies. Language, Nation Building and 'Race'. Farnham: Ashgate.

Meretoja, Hanna \& Aino Mäkikalli (toim.). Romaanin historian ja teorian kytköksiä. Suomalaisen Kirjallisuuden Seuran toimituksia 1405. Helsinki: SKS.

Mäkelä, Maria (toim.). Todellisuusefekti. Tutkielmia kirjallisista maailmasuhteista.

Kertomus ja tekstiteoria: Julkaisuja 1. Tampere: Tampereen yliopiston kieli-, käännösja kirjallisuustieteiden yksikkö.

Mäkikalli, Aino \& Liisa Steinby (toim.). Johdatus kirjallisuusanalyysiin. Tietolipas 238. Helsinki: SKS.

Paloposki, Outi \& H. K. Riikonen (toim.). Suomennetun tietokirjallisuuden historia 1800-luvulta 2000-luvulle. Suomalaisen Kirjallisuuden Seuran toimituksia 1289. Helsinki: SKS. 
Rastas, Anna (toim.). Kaikille lapsille. Lastenkirjallisuus liikkuvassa, monikulttuurisessa maailmassa. Tietolipas 240. Helsinki: SKS.

Rossi, Riikka \& Saija Isomaa (toim.). Kirjallisuuden naiset. Naisten esityksiä 1840luvulta 2000-luvulle. Suomalaisen Kirjallisuuden Seuran toimituksia 1391. Helsinki: SKS.

Snipes-Hoyt, Carolyn, Marie-Sophie Armstrong \& Riikka Rossi (eds). Re-reading Zola and Worldwide Naturalism. Miscellanies in Honour of Anna Gural-Migdal. Newcastle upon Tyne: Cambridge Scholars Publishing.

Steinby, Liisa \& Tintti Klapuri (eds). Bakhtin and His Others. (Inter)subjectivity, Chronotope, Dialogism. London et al.: Anthem.

Tuuri, Antti, Ulla Piela \& Seppo Knuuttila (toim.). Kirjailijoiden Kalevala. Kalevalaseuran vuosikirja 92. Helsinki: SKS. 